\title{
APONTAMENTOS SOBRE A TRISTEZA EM ESTUDANTES COM DEFICIÊNCIA INTELECTUAL A PARTIR DOS PRINCÍPIOS DA EDUCAÇÃO EMOCIONAL
}

\author{
NOTAS SOBRE LA TRISTEZA EN ESTUDIANTES CON DISCAPACIDAD \\ INTELECTUAL DESDE LOS PRINCIPIOS DE LA EDUCACIÓN EMOCIONAL
}
NOTES ON SADNESS IN STUDENTS WITH INTELLECTUAL DISABILITIES FROM THE PRINCIPLES OF EMOTIONAL EDUCATION

Taísa Caldas DANTAS ${ }^{1}$

\begin{abstract}
RESUMO: Este artigo tem como objetivo analisar a vivência da emoção da tristeza em estudantes com deficiência intelectual a partir dos princípios da Educação Emocional. Refletir sobre os estímulos geradores da tristeza pode levar o sujeito ao autoconhecimento e à ressignificação desses estímulos, principalmente em indivíduos que são vítimas de exclusão e vulnerabilidades, como é o caso das pessoas com deficiência intelectual. Nesse sentido, o campo da Educação Emocional surge como ferramenta pedagógica que deve ser incluída na escola, uma vez que oferece a possibilidade de o sujeito educar-se emocionalmente. Esta pesquisa adere à abordagem qualitativa e foi realizada com 27 estudantes com deficiência intelectual da Educação de Jovens e Adultos (EJA), a partir da observação direta e da realização de entrevista semiestruturada. As conclusões do estudo apontam que a emoção da tristeza em estudantes com deficiência intelectual precisa ser mais bem trabalhada e desenvolvida, através da implantação de projetos pedagógicos na área de Educação Emocional, uma vez que este campo possibilita a regulação emocional e uma vivência sadia da tristeza, permitindo que as pessoas com deficiência intelectual abram espaço para o novo e rompam com as inúmeras barreiras paralisantes que lhes são impostas socialmente.
\end{abstract}

PALAVRAS-CHAVE: Deficiência intelectual. Educação emocional. Tristeza.

RESUMEN: Este artículo tiene como objetivo analizar la experiencia de la emoción de tristeza en estudiantes con discapacidad intelectual a partir de los principios de la Educación Emocional. Reflexionar sobre los estímulos que generan tristeza puede llevar al sujeto al autoconocimiento y al replanteamiento de estos estímulos, especialmente en individuos que son víctimas de exclusión y vulnerabilidad, como es el caso de las personas con discapacidad intelectual. En este sentido, el campo de la Educación Emocional surge como una herramienta pedagógica que debe incluirse en la escuela, ya que ofrece la posibilidad de que el sujeto sea educado emocionalmente. Esta investigación se adhiere al enfoque cualitativo y se realizó con 27 estudiantes con discapacidad intelectual de Educación de Jóvenes y Adultos (EJA), a partir de la observación directa y entrevistas semiestructuradas. Las conclusiones del estudio señalan que la emoción de tristeza en estudiantes con discapacidad intelectual necesita ser mejor trabajada y desarrollada, a través de la implementación de proyectos pedagógicos en el área de Educación Emocional, ya que este campo posibilita la regulación

\footnotetext{
${ }^{1}$ Universidade Federal da Paraíba (UFPB), João Pessoa - PB - Brasil. Professora Adjunta vinculada ao Departamento de Habilitações Pedagógicas (DHP) do Centro de Educação. Doutorado em Educação (UFPB). ORCID: https://orcid.org/0000-0002-3661-0025. E-mail: taisa.cd@gmail.com
} 
emocional y una sana experiencia de tristeza. Permitir que las personas con discapacidad intelectual dejen espacio para lo nuevo y rompan con las muchas barreras paralizantes que se les imponen socialmente.

PALABRAS CLAVE: Discapacidad intelectual. Educación emocional. Tristeza.

ABSTRACT: This article aims to analyze the experience of the emotion of sadness in students with intellectual disabilities based on the principles of Emotional Education. Reflecting on the stimuli that generate sadness, can lead the subject to self-knowledge and the reframing of these stimuli, especially in individuals who are victims of exclusion and vulnerabilities, as is the case of people with intellectual disabilities. In this sense, the field of Emotional Education emerges as a pedagogical tool that should be included in the school, since it offers the possibility for the subject to be emotionally educated. This research adheres to the qualitative approach and was carried out with 27 students with intellectual disabilities in Youth and Adult Education (EJA), based on direct observation and semi-structured interviews. The conclusions of the study point out that the emotion of sadness in students with intellectual disabilities needs to be better worked and developed, through the implementation of pedagogical projects in the area of Emotional Education, since this field enables emotional regulation and a healthy experience of sadness, allowing people with intellectual disabilities to make room for the new and break with the many paralyzing barriers that are socially imposed on them.

KEYWORDS: Intellectual disability. Emotional education. Sadness.

\section{Introdução}

Este artigo tem como objetivo analisar a vivência da emoção da tristeza em estudantes com deficiência intelectual sob a perspectiva da Educação Emocional. O argumento central desse estudo é o de que refletir sobre os estímulos geradores da tristeza na vida de um indivíduo pode levá-lo ao autoconhecimento e à ressignificação dessas situações, principalmente em indivíduos que vivem sujeitos a uma realidade de exclusão, preconceito e vulnerabilidades, como é o caso das pessoas com deficiência intelectual.

O ser humano experimenta no decorrer de sua vida um turbilhão de emoções que são frequentemente vivenciadas de maneira inconsciente, sendo este um movimento não sadio para a vida cotidiana. Dentre o conjunto das emoções, as emoções primárias são aquelas inatas "e presentes em todas as culturas, revelando um padrão universal biológico de resposta, claramente identificado através do comportamento, da ativação corporal e da expressão facial" (POSSEBON, 2017b, p. 67). A tristeza, objeto de estudo desta pesquisa, apresenta-se como uma emoção básica e inata a qualquer ser humano. 
A tristeza é definida como uma emoção que se relaciona com perdas, seja no âmbito individual ou coletivo, quando a perda atinge alguém próximo ao indivíduo. Vivenciar a tristeza de forma sadia é fundamental para o bem-estar pessoal e a evolução humana, uma vez que esta emoção possui como uma de suas funções a renovação, de forma a proporcionar o rompimento com o passado e levar o indivíduo a se abrir para um novo ciclo de sua vida (MARTINS, 2004; POSSEBON, 2017a). Nesse sentido, a emoção da tristeza quando vivenciada de uma maneira saudável e adequada pode levar o indivíduo à superação de perdas e obstáculos que o paralisam. Por outro viés, caso esta emoção seja vivenciada de forma desregulada, pode levar a sua forma patológica, através de graves doenças como depressão e suicídio.

Muitos grupos socialmente marginalizados vivenciam frequentemente emoções como a tristeza. A história ilumina que não é de hoje que as experiências de exclusão marcam a vida das pessoas com deficiência, as quais permanecem em uma situação de desvantagem social intensa, especialmente no que se refere à "participação e aos direitos humanos básicos" (NEVES, 2005, p.48). Dentro deste grupo, as pessoas com deficiência intelectual ocupam um espaço ainda maior de vulnerabilidade social devido a todos os estigmas físicos e intelectuais que circundam suas vidas. Ademais, durante muito tempo essas pessoas foram impedidas de frequentar as escolas regulares, permanecendo trancafiadas em casa, vivendo à sombra de seus pais e/ou familiares (DANTAS, 2014).

Mesmo diante de todos os avanços e conquistas nos direitos das pessoas com deficiência, do aumento do acesso à escola regular e da adoção do modelo social da deficiência (ONU, 2006), percebe-se a perpetuação das barreiras que geram falta de oportunidades e uma série de restrições impostas pela sociedade (FARIAS, 2011) para este grupo social, o qual vivencia um turbilhão de emoções que são despercebidas pela escola e afetam seu desenvolvimento e aprendizagem.

Tradicionalmente o trabalho educacional das escolas têm se centrado em aspectos cognitivos, priorizando as aprendizagens científicas e técnicas, deixando de lado o conhecimento das pessoas e não se ocupando de refletir sobre os sentimentos e as emoções que estão na base do desenvolvimento integral (BISQUERRA, 2014). Na visão de Arandiga e Tortosa (2013), o campo da educação emocional surge exatamente para colaborar com a quebra da rigidez e falta de afetividade presentes nos espaços sociais. As emoções passam a ser vistas como essenciais ao desenvolvimento de todos os indivíduos, especialmente daqueles que são historicamente vítimas de marginalização e exclusão social, como ocorre com os jovens com deficiência intelectual. 
Este estudo adere à abordagem de pesquisa qualitativa e é fruto de uma investigação maior realizada no âmbito do Núcleo de Educação Emocional da Universidade Federal da Paraíba, com o foco de trabalhar as emoções como fator de prevenção à violência na escola pública, no período de 2016 a $2018^{2}$. Neste artigo, especificamente, serão apresentados os achados concernentes à emoção da tristeza com os alunos/as com deficiência intelectual. A pesquisa foi realizada em uma escola estadual paraibana e teve como participantes 27 jovens com deficiência intelectual matriculados em três turmas da Educação de Jovens e Adultos (EJA). Os instrumentos de coleta de dados utilizados foram a observação direta e um roteiro de entrevista semiestruturado denominado Diário das Emoções.

O artigo será dividido em três partes. Primeiramente, será apresentada uma breve discussão teórica sobre a emoção da tristeza, depois a metodologia da pesquisa e, por último, a análise dos principais estímulos geradores da tristeza em jovens com deficiência intelectual.

\section{Conceituando a emoção da tristeza e suas interfaces}

A tristeza constitui uma emoção básica ou primária e "está associada à perda de algo, de alguma pessoa querida, ou o que é valorizado: bens, saúde, situações pessoais e familiares, etc.” (GONSALVES, 2015, p. 31). A tristeza pode ser conceituada como uma reação energética geralmente associada a acontecimentos de perdas ou frustrações, no entanto, a literatura aponta (DAMÁSIO, 2013) que a tristeza não pode ser concebida como uma emoção negativa ou imprópria para o ser humano, uma vez que ela possui importantes funções para a vida, assim como qualquer outra emoção. Ademais, o campo emocional da tristeza pode vir acompanhado de sentimentos de dor, solidão, pessimismo, apatia, autopiedade, desânimo, depressão. Nas palavras de Bisquerra (2000, p. 103):

\section{A tristeza pode produzir uma perda da sensação de prazer. Já não se encontra prazer em atividades que até então haviam sido satisfatórias: uma boa comida, relações interpessoais, diversões. Se perde o interesse por tudo. A tristeza é uma emoção que não comporta tipos de ação pois a redução da atividade é sua maior característica.}

Devido às suas características peculiares descritas acima, não há dificuldades em identificar quando o sujeito está vivenciando a tristeza, uma vez que há a redução de atividades anteriormente comuns. A tristeza reconfigura toda a rede vivencial da pessoa, que passa a perder o interesse por coisas que gostava de fazer, começa a sentir-se impotente, sem

2 Esta investigação foi submetida e aprovada pelo Comitê de Ética, através do processo n. 61927916.8 .0000 .5188 
forças para resolver problemas, sem controle da situação. Culturalmente existem algumas dimensões que são reconhecidas por pertencerem à tristeza, como: isolamento, mutismo, lágrimas contidas ou derramadas (BRANT; MINAYO-GOMEZ, 2008), entre outras. Historicamente manifestar a tristeza em público tem sido visto como um tabu que gera desconforto e pode até ser considerado impróprio. Por isso, um trabalho pedagógico no campo da Educação Emocional é fundamental para a quebra desses paradigmas, uma vez que oportuniza o conhecimento acerca das emoções, gerando bem-estar subjetivo.

As pesquisas mostram que existem diversas formas de vivenciar as emoções (BISQUERRA; GONZÁLEZ; NAVARRO, 2015; DAMÁSIO, 2013), logo, é preciso conhecê-las, como se manifestam, e como elas podem ser funcionais para a vida. No caso da tristeza, caso seja vivenciada de forma saudável por curtos períodos, ela pode ser benéfica para o indivíduo que a experimenta. Por outro lado, caso a tristeza seja vivenciada por longos períodos, ela poderá se tornar patológica, como é o caso da depressão, mutilação e suicídio. Estudos apontam (CASASSUS, 2009; POSSEBON, 2017a) que o estilo de vida "pósmoderno" é um grande fator para o surgimento de alguns fenômenos e doenças, como a depressão e ansiedade, mas as soluções apresentadas até o momento são de tratamento e medicalização, poucas são as iniciativas que buscam a prevenção destas circunstâncias através de um trabalho com as emoções. Nesse contexto, destaca-se o quão fundamental é a escola investir não apenas em conteúdos e técnicas de aprendizagem, mas incluir também caminhos educativos que ensinem os estudantes a se autoconhecerem e a lidar com as emoções, para que tenham uma vida saudável e de sucesso em todos os âmbitos.

O suicídio se apresenta como a expressão máxima da tristeza patológica, quando esta se transforma em estado de ânimo. Nos dias atuais, o suicídio é considerado a segunda causa de internações de adolescentes de 10 a 19 anos do sexo feminino na rede SUS (FREITAS; BOTEGA, 2002). Ratificando esse dado, Benincasa e Resende (2006) apontam a tristeza como principal fator de risco para o suicídio entre adolescentes, não tendo diferenças muito relevantes entre aqueles de classe "A" e "D". No entanto, os autores destacam o "sentimento de desproteção" como uma peculiaridade da classe alta, e da necessidade de um grupo de apoio, como amigos, namorado(a) e familiares.

O maior fator de proteção contra a vivência da tristeza em suas formas patológicas identificado nos grupos das pesquisas realizadas por Benincasa e Rezende (2006) foi ter “alguém confiável para conversar". Isto destaca a importância de se estabelecer laços saudáveis através da educação emocional nas relações interpessoais, para que seja construída a confiança necessária e assertividade entre as pessoas. "Controlar ou negar o que se sente 
pode ocasionar muitos danos, pois as emoções podem permanecer alojadas indefinidamente em nosso corpo e em nossa mente, deixando suas consequências" (GONSALVES, 2015, p. 49). No caso das pessoas com deficiência intelectual, essa realidade é ainda mais agravada, uma vez que elas possuem poucos amigos para conversar e suas vozes são constantemente emudecidas.

É necessário prevenir a vivência negativa da tristeza, pois aprender a lidar com as circunstâncias que levaram a essa emoção e expandir os momentos de vitalidade podem proporcionar bem-estar subjetivo para se alcançar uma vida equilibrada. A tristeza possui importantes funções no ciclo da vida, uma vez que se interconecta com a despedida de uma etapa e a abertura para novos caminhos. Após vivenciá-la de maneira regulada e benéfica, se segue uma necessidade de descanso e de repouso, como a recuperação de um ferimento físico. E assim, ela gera uma espécie de renovação que prepara o indivíduo para um outro ciclo de sua história (MARTINS, 2004).

Por isso, é importante que esta emoção não seja negada ou negligenciada, mas vivenciada e trabalhada na escola e em todos os espaços que fazem parte da vida do sujeito. Não se pode conceber um mundo onde a racionalidade seja tão opositora das emoções, de forma que não seja permitido estar triste sem ser considerado sinal de fraqueza. A tristeza e o tempo da dor são necessários para uma vivência sadia da vida com todos os seus ciclos e recomeços, especialmente daqueles que sofrem constantemente situações de conflitos e discriminação, que podem ser possíveis estímulos geradores da tristeza, como ocorre com as pessoas com deficiência intelectual.

\section{Caminho metodológico}

Este artigo emerge no âmbito do Núcleo de Educação Emocional da Universidade Federal da Paraíba, através de uma investigação mais ampla com foco no estudo das emoções como fator de prevenção à violência na escola pública, a qual foi realizada entre os anos de 2016 e 2018. Neste artigo, especificamente, o foco da análise são os estímulos geradores da emoção da tristeza em estudantes com deficiência intelectual.

O campo da pesquisa foi uma escola estadual e os sujeitos participantes deste estudo foram 27 jovens com deficiência intelectual estudantes da Educação de Jovens e Adultos (EJA), sendo 17 jovens do sexo feminino e 10 do sexo masculino, na faixa etária de 16 a 35 anos. O critério de escolha desses participantes foi estar matriculado na turma de EJA e 
possuir acima de 15 anos, pois presumiu-se que esses estudantes teriam uma melhor percepção de si e expressão mais clara de seus sentimentos.

Para a coleta dos dados foram utilizados dois instrumentos de pesquisa. O primeiro foi a observação direta realizada pelo pesquisador, onde foram registrados em um diário de bordo todas as percepções e sentimentos vivenciados durante o contato com os jovens. O segundo foi um roteiro de entrevista semiestruturado, denominado Diário das Emoções, o qual contêm perguntas abertas sobre quais situações poderiam desencadear determinadas emoções básicas (medo, raiva, alegria, tristeza, dentre outras), solicitando ao respondente uma descrição do evento. Cada página do Diário correspondeu a uma emoção.

O roteiro de entrevista foi construído e aplicado pela equipe do projeto de pesquisa, constituída por pesquisadores em educação, e também validado por pares. A aplicação da entrevista foi feita presencialmente nos meses de janeiro a março de 2018. Todos os/as alunos/as presentes na sala de aula aceitaram participar da pesquisa, não havendo nenhuma rejeição. Devido às dificuldades de leitura e escrita dos estudantes com deficiência intelectual, a entrevista foi realizada de maneira que eles/as pudessem responder oralmente às perguntas. Foram cumpridas todas as exigências científicas e éticas, incluindo a confidencialidade, o consentimento da escola e das famílias e a aprovação da pesquisa no Comitê de Ética.

No momento anterior à aplicação do roteiro de entrevista, também foram realizadas vivências em Educação Emocional, com o intuito de trazer uma maior clareza e conscientização sobre as emoções para os sujeitos da pesquisa. No caso da vivência sobre a "tristeza", foram utilizados recursos como fotografias, pintura, música, técnica de relaxamento, sendo foi dividida em cinco momentos:

1. Contato inicial com a turma e apresentação da emoção "tristeza" com a utilização de recursos, imagens de expressões faciais e música.

2. Apresentação de um livro com imagens fotográficas de situações que remetessem à emoção.

3. Técnica de relaxamento com o auxílio de música, após um diálogo com a turma e pergunta oral sobre a emoção contida no Diário, além de registro das respostas coletadas com auxílio de um gravador de voz.

4. Após a coleta foi proposta uma atividade (pintura).

5. Finalização da intervenção, com recolhimento de pinturas, além de agradecimentos a alunos/as e professora. 
Após a coleta das informações por meio das vivências e da aplicação do roteiro de entrevista, passamos então para a fase de transcrição dos áudios e caracterização das respostas, através do desenvolvimento de categorias de informação. Cada página do Diário das Emoções correspondente a uma emoção, que foi identificada pela letra inicial da emoção e pelo número do participante: por exemplo, T.08 (emoção tristeza, participante número 08); T.02 (emoção tristeza, participante número 02). Tal procedimento permitiu selecionar categorias principais considerando a recorrência do fenômeno.

A seguir, apresentamos a análise dos dados relativos aos estímulos geradores da emoção da tristeza pelos jovens com deficiência.

\section{A vivência da tristeza em jovens com deficiência intelectual}

A partir dos dados coletados foi possível identificar os estímulos geradores da emoção da tristeza na vida de jovens com deficiência intelectual. Possebon (2017b) afirma que não é qualquer situação que tem o poder de desencadear uma emoção, pois, para que a situação emocione, ela precisa ser um Estímulo Emocional Competente - EEC. Este termo foi criado por António Damásio (2013) para designar um evento relevante ou um ativador emocional capaz de gerar uma resposta no organismo a partir da avaliação que a pessoa faz da situação. A respeito dos estímulos emocionais competentes, Martins (2004, p. 65) enriquece o entendimento ao afirmar que "de início as emoções são provocadas por situações e objetivos concretos [...] mais tarde, ativadores simbólicos, psicológicos e sociais são adicionados aos concretos".

Nesta pesquisa, foi possível elencar como um dos principais desencadeadores da tristeza em jovens com deficiência intelectual a saudade, refletida principalmente pelas memórias de quem não está mais no convívio do sujeito ou pela morte de entes queridos. Esse dado aponta que a tristeza além de estar relacionada com perdas materiais e humanas, está diretamente ligada ao apego através dos laços afetivos familiares (POSSEBON, 2017b), conforme mostrado nas falas a seguir:

\footnotetext{
“...eu sinto saudades do meu falecido avô, ele era muito importante pra mim” (T.02);

"Fico sozinha em casa, ai me lembro da minha mãe, que Deus a tenha, ela já se foi, ai fico triste" (T.10);

“...o que me deixa triste é que eu perdi meu tio. Eu amava ele.” (T.23).
}

A experiência familiar constitui o primeiro núcleo através do qual os jovens (com ou sem deficiência) experimentam conflitos e a vivência de suas emoções, sendo, portanto, 
fundamental para o desenvolvimento biopsicossocial dos indivíduos e determinante para a estruturação de processos de regulação emocional (PRATTA; SANTOS, 2017). De acordo com Retana-Franco e Sánchez-Aragón (2008), "la regulación emocional se refiere a las maneras de modular, inhibir, intensificar o disminuir la forma de reaccionar ante situaciones elicitadoras de emoción" (p. 180), e esse processo se inicia desde os primeiros dias de vida no seio familiar, se aprimorando durante o período da adolescência e juventude.

A saudade expressa nos depoimentos dos jovens acima se tornou gatilho para a emoção da tristeza, pois em todas as falas a saudade está relacionada a alguém muito próximo, parte da rede de apoio familiar do/a jovem. Como afirma Possebon (2017a, p. 33), "para se sentir triste pela morte ou ausência de alguém, esse alguém deve ter um vínculo emocional com a pessoa que está triste" e ter influência direta com o seu bem-estar. Cabe destacar que as perdas familiares também foram apontadas como forte desencadeador da tristeza em adolescentes sem deficiência na pesquisa realizada por Gonsalves (2015), destacando-se que esse é um fator universal gerador da tristeza em indivíduos de todas as idades, culturas, classes sociais, gênero etc.

A despeito de todos os avanços político-legais relacionados aos direitos das pessoas com deficiência, inclusive no que diz respeito a mecanismos de proteção contra atitudes exclusionárias, as pessoas com deficiência e, mais precisamente as que possuem deficiência intelectual, continuam a sofrer diversas formas de discriminação em suas vidas. Nessa pesquisa, a existência de relações conflitivas e preconceituosas praticadas por familiares e conhecidos surge como outro estímulo emocional competente da tristeza que pode ser registrado nas falas dos jovens:

"O motorista lá de onde eu moro não gosta de mim, nem da minha mãe, só porque eu tenho deficiência" (T.07);

"Minha tia, ela diz coisa ruim comigo que me deixa muito triste" (T.15);

"O que me deixa mais com vontade de chorar é as meninas lá da comunidade, que ficam o tempo todo mexendo comigo, tirando onda da minha cara" (T.06).

Esses depoimentos revelam comportamentos agressivos traduzidos em violência simbólica através de palavras de rejeição, uma vez que, nessa fase da vida, a aceitação do grupo passa a ter papel extremamente relevante. Esse fator está presente no campo emocional da tristeza de jovens com ou sem deficiência, conforme estudo realizado por Mooij (2011), onde 80.770 estudantes relataram ser vítimas de violência verbal e apontaram como principais motivos para a discriminação: aparência física, comportamentos individuais, nível de 
desempenho escolar, deficiência física ou intelectual, aspectos religiosos, questões de gênero e orientação sexual.

Williams (2003) define como ato violento "qualquer ação que se caracteriza pela inércia, pela passividade, e pelo silêncio, de modo que, quando a atividade e a fala de outrem são impedidas ou anuladas, há violência" (p. 23). No caso da pessoa com deficiência intelectual essa violência simbólica está ainda mais presente, uma vez que a invisibilidade deste grupo social está na raiz de sua vulnerabilidade aa violências, seja verbal, física, psicológica ou sexual (FERREIRA, 2008). Por outro lado, as condutas agressivas de rejeição são tradicionalmente admitidas como naturais dentro da escola e da comunidade em geral, sendo habitualmente ignoradas ou não valorizadas, tanto pelos professores quanto pelos pais e amigos.

Somado à rejeição, o abandono também foi apontado nessa pesquisa como estímulo gerador da emoção da tristeza nos jovens com deficiência intelectual. $\mathrm{O}$ abandono de crianças com deficiência tem sido realizado historicamente em diversas culturas que toleram essas práticas, uma vez que a deficiência foi vista por muito tempo sob a ótica da concepção médico-patológica como uma doença ou um "carma" de que as famílias poderiam "se livrar" (MAZZOTA, 2005; MELETTI; BUENO, 2011). Mesmo diante da concepção de direitos humanos sendo defendida desde o século passado com a Declaração Universal dos Direitos Humanos (ONU, 1948) e com a consolidação do modelo social da deficiência (ONU, 2006), que inaugurou um novo olhar sobre a deficiência sob a ótica da diversidade humana, continuam a se perpetuar crenças infundadas sobre o desenvolvimento e capacidade das pessoas com deficiência intelectual, ensejando, também, em práticas veladas de abandono.

As autoras Fonseca, Santos e Dias (2009) analisaram os motivos que levam pais e mães a abandonarem crianças com deficiência, colocando-as sob a responsabilidade de outras instituições ou de outros familiares, concluindo que além das barreiras relacionadas à deficiência que pesam para o abandono desses menores, "geralmente, trata-se de pais e mães que carregam consigo sua própria história de carência e abandono" (p. 303), não tendo condições psicológicas e sociais de assumir aquela criança. Os jovens participantes desse estudo expressam essa realidade ao afirmarem:

\footnotetext{
"minha mãe me abandonou, pois ela era sozinha e não tinha mais condições de me criar, além de está muito triste com a vida" (T.23);

"Meu pai me abandonou quando eu tinha dois anos, pois ele perdeu o emprego e não sabia como me criar" (T.18).
} 
Luterman (1987) ressalta que pais, assim como mães, parecem vivenciar angústia, ansiedade e descompensação emocional ao receberem o diagnóstico da deficiência de seus filhos/as. Todos esses sentimentos inerentes ao processo de aceitação da deficiência, caso não sejam vivenciados de forma adequada e no tempo certo, podem levar ao abandono de crianças e adolescentes com deficiência. As falas acima apontam para esta realidade, pela qual os pais e/ou mães dos jovens participantes passaram e não souberam como superar, culminando em histórias de abandono. Nesse contexto, a educação emocional pode ser um caminho para auxiliar esses pais e mães a fortalecerem suas emoções e ressignificar a tristeza e desespero que estão sentindo, uma vez que, como argumenta Casassus (2009, p. 42): "a maioria dos problemas dos indivíduos na atualidade são de ordem emocional e não cognitiva".

Outro fator apontado nesta pesquisa como desencadeador da tristeza em jovens com deficiência intelectual é serem privados de frequentar a escola. Sabe-se que por muito tempo esse grupo foi proibido de frequentar as escolas regulares, permanecendo trancafiados em casa e tendo suas vidas restritas ao convívio familiar, "[...] o que tornava essas pessoas incapazes de enfrentar e aprender a administrar a vida em sociedade" (GODOY, 2002, p. 33). Tal invisibilidade social e a omissão das lideranças políticas na efetivação dos seus direitos geraram falta de oportunidades e não acesso à educação (FARIAS, 2011; DANTAS, 2011). Hoje ainda existem resquícios sociais e psicológicos desse período de privação e o discurso dos jovens ratifica o fato de que não ir à escola os deixam muito tristes:

"Quando não tem ônibus para vir para escola eu fico muito triste, pois é o único lugar que tenho pra onde sair" (T.10);

"Quando não venho para a escola eu choro muito porque não encontro meus amigos e fico em casa sem fazer nada, só assistindo televisão" (T.27).

O paradigma da educação inclusiva é um produto desta época e foi consolidado com a Declaração de Salamanca (UNESCO, 1994), a partir da qual foi questionado o não acesso à educação formal e a evasão escolar de todos os estudantes que apresentam necessidades educativas especiais por serem pessoas com deficiência, superdotados, moradores de rua, de minoria cultural ou qualquer grupo que seja marginalizado na sociedade. A partir dessa conquista, a exemplo do que os depoimentos dos jovens acima revelam, a escola tornou-se um local de apropriação para eles/as, de identidade, de desenvolvimento pessoal e construção de uma rede de apoio e amigos/as.

Essa realidade difere do que foi analisado pela pesquisa realizada por Coutinho, Carneiro e Salgueiro (2018) a respeito das vozes das crianças e adolescentes sem deficiência sobre a escola, onde foi revelado que grande parte das crianças e adolescentes não mantêm 
uma boa relação com a escola, nem encontram nela um espaço afetivo e de bem-estar. A escola é considerada, na percepção dos adolescentes sem deficiência, fonte de tristeza, principalmente quando se sentem fracassados por não conseguirem o resultado escolar que almejam e relatam sentirem-se ainda mais tristes quando se sentem cobrados por algo que não conseguem dar, não encontrando ninguém no ambiente escolar que possa ajudá-los e acolhêlos.

No caso das pessoas com deficiência, para além do caráter normativo do direito à educação, é através de processos educacionais que ocorrem na escola (e também fora dela) que essas pessoas aprendem sobre suas identidades (WOODWARD, 2000) e desenvolvem habilidades e competências necessárias para ter uma vida independente. Nesse sentido, a escola enquanto espaço social deve incluir em seus objetivos oferecer uma educação de qualidade para as pessoas com deficiência e também compreender a importância do seu papel como agente de proteção da invisibilidade e vulnerabilidade desse grupo social, como ratifica Ferreira (2009, p. 50): “os educadores devem se comprometer com a remoção das situações que geram vulnerabilidade, ao mesmo tempo em que asseguram sua educação em condições igualitárias".

Esta pesquisa aponta que apesar de todos os desafios e barreiras que ainda existem na escola regular para garantir uma educação de qualidade para as pessoas com deficiência intelectual, a escola representa para eles/as um ambiente acolhedor e desencadeador de alegrias. Todos os jovens participantes desta pesquisa identificaram a escola como um local de boas relações e não revelaram motivos de tristeza dentro da escola e sim na ausência desta. Por outro lado, a pesquisa realizada por Maia e Medrado (2020) mostrou que jovens com deficiência intelectual também podem se sentirem desprotegidos na escola e serem estigmatizados por não se enquadrarem no padrão de aprendizado estabelecido.

Pletsch e Glat (2012) confirmam essa realidade ao identificarem que a escola, ao mesmo tempo em que colabora com a desenvolvimento social e integral dos estudantes com deficiência, muitas vezes também pode contribuir na "[...] cristalização da deficiência, seja por seu olhar limitante sobre as pessoas com deficiência intelectual, seja por seu modelo de supervalorização das habilidades cognitivas, tornando essas pessoas inelegíveis à aprendizagem, na concepção dos educadores” (p. 12). Assim, a escola também pode ser um instrumento de colaboração para a baixa autoestima dos jovens com deficiência, sendo esse um dos grandes entraves que esse grupo enfrenta na conquista da autonomia.

Essa pesquisa aponta como outro estímulo gerador da tristeza nos jovens com deficiência intelectual o ser desacreditado e a percepção negativa de si, sendo esses dois 
fatores recorrentes em diversas situações do dia a dia desses jovens, seja no âmbito familiar, escolar ou em meio à roda de amigos/as:

"Quando minha professora e alguns amigos não acreditam em mim, eu fico magoada"; (T.10)

"Meu corpo é feio, eu não acho bonito, não gosto". (T.24)

"Eu tenho uma tia que cuida de mim e ela nunca deixa eu cozinhar, porque ela acha que não consigo" (T.05).

As vozes dos jovens refletem a absorção do discurso negativo que seus pares, familiares e professores/as têm sobre eles e o reflexo desta realidade na formação de sua identidade. Todos os mecanismos de coação e segregação aos quais os jovens com deficiência intelectual são submetidos trazem consequências na formação de sua identidade, no processo de socialização e nas relações de afetividade com o meio (SHIMONO, 2008). Sobre isto, Mantoan (2008) afirma que quando as pessoas com deficiência intelectual percebem a imagem limitante que os outros têm sobre elas no sentido de acreditarem que o sucesso escolar e profissional está fora de seu alcance, essa percepção negativa irá inibir a utilização de meios para superar tais barreiras.

A maioria dos desafios relacionados com a autoimagem e a autoestima têm raízes na forma como se desenrola o processo de lidar com as emoções (MARTINS, 2004), de modo que caso os sujeitos não tenham consciência da sua real imagem, permanecem duplamente vulnerabilizados porque são jovens e porque são pessoas com deficiência e sem confiança em si, condições que imprimem limites nas possibilidades de participação social. Por outro lado, Worrell (2010) discute que o primeiro passo para romper com esse estado é adquirir autoestima e autoconfiança, de forma que o indivíduo quebre com a crença na "incapacidade" causada pela deficiência e passe a ter uma nova referência de si. Esta é a base para ter uma vida autônoma, pois ao ter confiança em si e em suas habilidades o indivíduo ganha força para resistir às relações de poder que o assujeitam.

Outro fator desencadeador da tristeza nesta pesquisa foi a solidão, onde um número significativo dos jovens com deficiência intelectual afirma que se sentem sozinhos e não conseguem firmar laços de amizade:

"Eu não tenho nenhum amigo pra sair comigo e me sinto triste por isso" (T.02)

"Eu queria que minha mãe conversasse mais comigo, dos meus sonhos pra vida" (T.11)

"Algo que me deixa muito triste é não ter muitos amigos, fico sozinha o tempo todo" (T.25)

"Eu queria poder sair pro shopping e conversar mais com amigos. Eu só 
tenho a minha avó" (T.18)

Nos depoimentos acima se verifica uma recorrência significativa de um conjunto de situações que levam ao isolamento social dos jovens, como falta de atenção, a ausência de amigos/as, a exclusão propriamente dita, privando-os da convivência com os demais, como se fossem invisíveis. Historicamente as pessoas com deficiência têm construído suas vidas mais restritas ao convívio no âmbito familiar, e atividades que são comuns para adolescentes e jovens sem deficiência, como sair com os amigos para ter diversão, acaba sendo algo raro para este grupo social.

O estudo de Fernández-Abascal et al. (2015) mostra que o estabelecimento de pelo menos um vínculo social adequado pode proteger adolescentes e jovens de comportamentos depressivos, uma vez que a ausência de pessoas disponíveis e confiáveis para ouvi-los provoca outros sentimentos, como: abandono, rejeição e vazio. Esta realidade pode contribuir na elaboração de pensamentos ruminantes, destrutivos e pessimistas, os quais estão relacionados com a emoção da "tristeza" e pode levar à depressão (POSSEBON, 2017b). É preciso criar mecanismos de prevenção, pois estima-se que o risco de depressão aumenta com a adolescência, sendo a sua prevalência estimada em cerca de $2 \%$ nas crianças e em $4-8 \%$ nos adolescentes. Em relação às meninas na adolescência, elas têm duas vezes maior risco de desenvolver depressão do que os rapazes da mesma idade (RESENDE et al., 2013).

Uma escolarização baseada nos princípios da educação emocional é um caminho eficaz para trabalhar a tristeza na vida de jovens e adolescentes com deficiência intelectual, para que essa emoção não se manifeste em suas formas patológicas. Nesse sentido, a escola não pode priorizar apenas os conteúdos científicos e técnicos, deixando de lado os aspectos afetivos e emocionais que afetam o sujeito em desenvolvimento. Nas palavras de Arándiga (2015, p. 3), a escola deve dispor "de um currículo que defina o desenvolvimento dos conteúdos emocionais com seus elementos curriculares correspondentes: objetivos, atividades, metodologia e critérios de avaliação", para que sejam trabalhadas as emoções dos estudantes com e sem deficiência.

Principalmente em relação aos jovens que são vítimas de situações de vulnerabilidade e exclusão, como é o caso das pessoas com deficiência intelectual, a educação emocional surge como meio de prevenção aos fatores de risco, uma vez que o desconhecimento sobre como as emoções influenciam na aprendizagem e na condução de vida não permite que o sujeito rompa com as barreiras que o paralisam. A escola, então, precisa dispor de metodologias que levem os discentes a vivenciarem um processo de autoconhecimento e 
conscientização de suas emoções, para que assim não ajam inconscientes dos efeitos que as emoções têm sobre si.

Nesse sentido, ao tomarem consciência dos estímulos que os levam a sentirem a emoção da tristeza, os jovens com deficiência intelectual podem avaliar, compreender e ressignificar como lidar com essa emoção. Esse processo pode contribuir no enfrentamento de situações difíceis e oportunizar a saída de um estado de vulnerabilidade para um estado de autonomia e independência de vida.

\section{Considerações finais}

Esta pesquisa teve como objetivo analisar os principais estímulos que geram a emoção da tristeza em estudantes com deficiência intelectual, a partir dos princípios da Educação Emocional. Os dados deste estudo evidenciam como principais fatores que podem levar adolescentes e jovens com deficiência intelectual a vivenciarem a emoção da tristeza: a saudade de entes queridos; atitudes e palavras de rejeição; abandono; ausência da escola; ser desacreditado e ter uma percepção negativa de si; a solidão, refletida principalmente na ausência de amigos/as e pessoas confiáveis para ouvi-los.

Esse estudo apontou através das vozes dos jovens participantes que a condição da deficiência insurge em diversas situações de exclusão, preconceito e invisibilidade social que se constituem obstáculos para que as pessoas com deficiência possam construir suas vidas de maneira independente a partir de conceitos firmados de autoestima e autoaceitação positivos. No caso da emoção da tristeza, que tantas vezes é vivenciada a partir dessas situações, se as pessoas com deficiência passarem por um processo de educação emocional e aprenderem a vivenciá-la de maneira saudável, a tristeza será momentânea e se tornará uma fortaleza para a superação de tais barreiras. A tristeza, pois, é uma emoção que possui dentre as suas importantes funções a renovação de ciclos e a quebra de condições que paralisam e trazem sofrimento para os sujeitos.

É fundamental, portanto, que a Educação Emocional enquanto campo do conhecimento seja incluída na escola, pois o processo de ensino-aprendizagem deve estabelecer em seu currículo não apenas os aspectos cognitivos, mas também incluir as dimensões afetivas e emocionais que fazem parte do desenvolvimento integral dos sujeitos. A vivência de um processo de conscientização das emoções leva à vivência mais saudável das mesmas, uma vez que possibilita o desenvolvimento de competências socioemocionais 
alinhadas à construção de uma identidade própria, tão importante para as pessoas com deficiência intelectual se reconhecerem como sujeito de direitos e de valor integral.

São necessárias maiores investigações e intervenções pedagógicas que tragam a discussão da Educação Emocional para a escola, objetivando a quebra da rigidez dos conteúdos curriculares, trazendo um olhar mais sensível em relação à diversidade e todas as questões envoltas nesta. Portanto, é essencial que no espaço escolar haja um trabalho mais acurado e direcionado para as emoções dos discentes, principalmente daqueles que possuem alguma deficiência ou são vítimas de situações de preconceito e exclusões diversas. Destacase também a importância de um trabalho em educação emocional que seja extensivo a toda a família dos discentes, já que o seio familiar constitui o ambiente inicial em que se dão as vivências emocionais.

\section{REFERÊNCIAS}

ARÁNDIGA, A. V. Los programas de educación emocional en la escuela. In: SEMINÁRIO INTERNACIONAL DE EDUCAÇÃO EMOCIONAL, 2015, João Pessoa. Anais [...]. João Pessoa, 2015. 1 CD.

ARÁNDIGA, A. V.; TORTOSA, C. V. Inteligencia emocional: aplicaciones educativas. Valencia: Editorial Promolibro, 2013.

BENINCASA, M. REZENDE, M. M. Tristeza e suicídio entre adolescentes: fatores de risco e proteção. Boletim de psicologia, v. 56, n. 124, p. 93-110, 2006. Disponível em: http://pepsic.bvsalud.org/pdf/bolpsi/v56n124/v56n124a07.pdf. Acesso em: 10 fev. 2020.

BISQUERRA, R. A. Educación emocional y bienestar. Barcelona: Praxis, 2000.

BISQUERRA, R. A. (Coord.). Prevención del acoso escolar con educación emocional. Bilbao: Editorial Desclée de Brouwer, 2014.

BISQUERRA, R. A.; GONZÁLEZ, J. C. P.; NAVARRO, E. G. Inteligencia emocional en educación. Madrid: Sintesis, 2015.

BRANT, L. C.; MINAYO-GOMEZ, C. Da tristeza à depressão: a transformação de um malestar em adoecimento no trabalho. Interface - Comunicação, Saúde, Educação. v. 12, n. 26, p. 667-676, 2008. Disponível em: https://www.scielo.br/scielo.php?pid=s141432832008000300017\&script=sci_abstract\&tlng=pt. Acesso em: 20 jul. 2020.

CASASSUS, J. Fundamentos da educação emocional. Brasília: UNESCO/Liber Editora, 2009.

COUTINHO, L. G.; CARNEIRO, C.; SALGUEIRO, L. M. Vozes de crianças e adolescentes: o que dizem da escola? Psic. Esc. Edu., Maringá, v. 22, n. 1, jan./abr. 2018. Disponível em: 
https://www.scielo.br/scielo.php?pid=S1413-

85572018000100185\&script=sci abstract\&tlng=en. Acesso em: 15 ago. 2020.

DAMÁSIO, A. Em busca de espinosa: prazer e dor na ciência dos sentimentos. São Paulo: Companhia das Letras, 2013.

DANTAS, T. C. Jovens com deficiência como sujeitos de direito: o exercício da autoadvocacia como caminho para o empoderamento e a participação social. 2011. $141 \mathrm{f}$. Dissertação (Mestrado em Educação) - Universidade Federal da Paraíba, João Pessoa, 2011.

DANTAS, T. C. Estudo da autoadvocacia e empoderamento de pessoas com deficiência no Brasil e no Canadá. 2014. Tese (Doutorado em Educação) - Universidade Federal da Paraíba, João Pessoa, 2014.

FARIAS, A. Q. Gênero e deficiência: vulnerabilidade feminina, ruptura e superação. 2011. Dissertação (Mestrado em Educação) - Universidade Federal da Paraíba, João Pessoa, 2011.

FERNÁNDEZ-ABASCAL, E. G. et al. Psicología de la emoción. Madrid, Editorial Ramón Areces, 2015.

FERREIRA, W. B. Entendendo a discriminação contra estudantes com deficiência na escola. In: FÁVERO, O. et al. (org.). Tornar a educação inclusiva. Brasília, DF: UNESCO: 2009.

FERREIRA, W. B. Vulnerabilidade à violência sexual no contexto da escola inclusiva: reflexão sobre a invisibilidade da pessoa como deficiência. REICE. Revista Iberoamericana sobre Calidad, Eficacia y Cambio en Educación, v.6, n. 2, p. 120-136, 2008.

FONSECA, C. M. S. M. S.; SANTOS, C. P.; DIAS, C. M. S. B. D. A adoção de crianças com necessidades especiais na perspectiva dos pais adotivos. Paidéia, v. 19, n. 44, 303-311, set./dez. 2009. Disponível em: https:/www.scielo.br/pdf/paideia/v19n44/a03v19n44.pdf. Acesso em: 05 fev. 2020.

FREITAS, G. V. S.; BOTEGA, N. J. Gravidez na adolescência: prevalência, ansiedade e ideação suicida. Revista da Associação Médica Brasileira, v. 48, n. 3, p. 198-199, 2002. Disponível em: https://www.scielo.br/scielo.php?script=sci_arttext\&pid=S010442302002000300039. Acesso em: 03 set. 2020.

GODOY, H. P. Inclusão de alunos portadores de deficiência no ensino regular paulista: recomendações internacionais e normas oficiais. São Paulo: Mackenzie, 2002.

GONSALVES, E. P. O livro das emoções: uma abordagem neurofísiológica, comportamental e educativa dos estados emocionais. Curitiba: CRV, 2015.

LUTERMAN, D. Deafness in the family. Boston: Little Brown and Company, 1987.

MAIA, A. A. M.; MEDRADO, B. P. (org.). Síndrome de Down: vozes e dimensões da inclusão escolar. Campinas: Pontes Editores, 2020.

MANTOAN, M. T. É. O desafio das diferenças nas escolas. Petrópolis: Vozes, 2008. 
MARTINS, J. M. A lógica das emoções na ciência e na vida. Petrópolis: Editora Vozes, 2004.

MAZZOTTA, M. J. S. Educação especial no Brasil: história e políticas públicas. 5. ed. São Paulo: Cortez, 2005.

MELETTI, S. M. F.; BUENO, G. S. O impacto das políticas públicas de escolarização de alunos com deficiência: uma análise dos indicadores sociais no Brasil. Linhas Críticas, Brasília, v. 17, n. 33, p. 367-383, maio/ago. 2011. Disponível em: http://ppeees.ufms.br/wpcontent/uploads/2016/02/meletti-bueno-2011-linhas-criticas.pdf. Acesso em: 03 fev. 2020.

MOOIJ, T. Differences in pupil characteristics and motives in being a victim, perpetrator and witness of violence in secondary education. Rev Papers Educ., v. 26, n. 1. p. 105-122, 2011. Disponível em: https:/www.tandfonline.com/doi/abs/10.1080/02671520903191196. Acesso em: 03 fev. 2020.

NEVES, T. R. L. Educar para a cidadania: promovendo a autoadvocacia em grupos de pessoas com deficiência. 2005. Tese (Doutorado em Educação) - Especial da Universidade Federal de São Carlos, São Carlos, 2005.

ONU. Declaração Universal dos Direitos Humanos. 1948. Disponível em: http://www.mj.gov.br/sedh/ct/legis_intern/ddh_bib_inter_universal.htm. Acesso em: $10 \mathrm{dez}$. 2019.

ONU. Convenção sobre os Direitos das Pessoas com Deficiência. 2006. Disponível em: http://www.assinoinclusao.org.br/downloads/convencao.pdf. Acesso em: 10 dez. 2019.

PLETSCH, M. D.; GLAT, R. A escolarização de alunos com deficiência intelectual: uma análise da aplicação do plano de desenvolvimento educacional individualizado. Linhas Críticas, Brasília, v. 18, n. 35, p. 193-208, jan./abr. 2012. Disponível em: https://periodicos.unb.br/index.php/linhascriticas/article/view/3847/3518. Acesso em: 10 mar. 2020.

POSSEBON, E. G. As emoções básicas: medo, tristeza e raiva. Libellus. João Pessoa, 2017a.

POSSEBON, E. G. O universo das emoções: uma introdução. Libellus. João Pessoa, 2017b.

PRATTA, E. M. M.; SANTOS, M. A. Família e adolescência: a influência do contexto familiar no desenvolvimento psicológico de seus membros. Psicologia em Estudo, v. 12, n. 2, p. 247-256, maio/ago. 2007. Disponível em: https://www.scielo.br/scielo.php?pid=S141373722007000200005\&script=sci_abstract\&tlng=pt. Acesso em: 02 ago. 2020.

RESENDE, C. et al. Depressão nos adolescentes: mito ou realidade? Nascer e Crescer, v. 22, n. 3, set. 2013. Disponível em: http://www.scielo.mec.pt/scielo.php?

script=sci_arttext\&pid=S0872-07542013000300003. Acesso em: 05 fev. 2020.

RETANA-FRANCO, B. E.; SANCHÉZ-ARAGÓN, R. Rastreando en el pasado... formas de regular la felicidad, la tristeza, el amor, el enojo y el miedo. Universitas Psychologica, v. 9. n. 1, 2010. Disponível em: http://www.scielo.org.co/pdf/rups/v9n1/v9n1a15.pdf. Acesso em: 10 ago. 2020. 
SHIMONO, S. O. Educação e trabalho: caminhos da inclusão na perspectiva da pessoa com deficiência. 2008. Dissertação (Mestrado em Educação) - Faculdade de Educação, Universidade de São Paulo, São Paulo, 2008.

UNESCO. Declaração de Salamanca. Sobre Princípios, Políticas e Práticas na Área das Necessidades Educativas Especiais. 1994.

WILLIAMS, L. C. A. Sobre a deficiência e violência: reflexões para uma análise de revisão de área. Rev. Bras. Ed.Esp., Marília, v. 9, n. 2, p. 141-154, jul./dez. 2003. Disponível em: https://www.abpee.net/homepageabpee04_06/artigos_em_pdf/revista9numero2pdf/ 2williams.pdf. Acesso em: 03 fev. 2020.

WOODWARD, K. Identidade e diferença: uma introdução teórica e conceitual. In: SILVA, T. T. Identidade e diferença: a perspectiva dos estudos culturais. Petrópolis: Vozes, 2000.

WORRELL, B. People first: advice for advisors. Downsview, Ontario, 2010.

\section{Como referenciar este artigo}

DANTAS, T. C. Apontamentos sobre a tristeza em estudantes com deficiência intelectual a partir dos princípios da educação emocional. Revista Ibero-Americana de Estudos em Educação, Araraquara, v. 16, n. 3, p. 1929-1947, jul./set. 2021. e-ISSN: 1982-5587. DOI: https://doi.org/10.21723/riaee.v16i3.13902

Submetido em: 06/07/2020

Revisões requeridas em: 13/01/2021

Aprovado em: 10/02/2021

Publicado em: 01/07/2021 